\title{
Vectors of Efficiency in Hybrid Poplar Genotype Testing
}

\author{
Neil D. Nelson*, William E. Berguson, Bernard G. McMahon, Meijun Cai, Daniel J. Buchman
}

Natural Resources Research Institute, University of Minnesota Duluth, 5013 Miller Trunk Highway, Duluth, MN 55811-1442, USA

*Corresponding author: Neil D. Nelson, Email: nnelson2@d.umn.edu

\begin{abstract}
The Natural Resources Research Institute Hybrid Poplar Program breeds and tests genetically improved clones for biomass production and environmental services. The testing process progresses from Nursery Progeny Tests (NPT) to Family Field Trials (FFT) to Clone Trials (CT) to Yield Blocks (YB), with limited replication of many clones in FFT and CT and a limited number of highly selected clones set out in monoclonal blocks (YB) to approximate the conditions of commercial plantations. We used correlation vectors, $\mathrm{R}^{2}$ (coefficient of determination) and $r_{s}$ (Spearman's Coefficient) for growth $\left(\mathrm{DBH}^{2}\right)$ and McFadden's Pseudo $\mathrm{R}^{2}$ for canker severity score, to determine where testing times could be altered (age - age correlations) and whole testing steps eliminated. FFT can be shortened from 5 years to 4 years. In CT, rank correlations between age 5 (half-rotation) and age $9 / 10$ (full rotation) were significant $\left(R^{2}=\right.$ $0.39-0.72)$, but age 5 selection missed $44 \%$ of the top ten clones at age $9 / 10$. Clone rank in CT at full, but not half, rotation was correlated with rank at full rotation in YB. Choosing clones at 9 years in $\mathrm{CT}$ adds 4 years but allows possible elimination of YB for clone selection. Both FFT and CT are necessary. Canker abundance and severity in CT at full rotation cannot be determined at earlier ages. An aggressive strategy saves 6 years of testing.
\end{abstract}

Common abbreviations in this paper are as follows: $\mathrm{CP}=$ controlled pollination; NPT = nursery progeny test; $F F T=$ family field trial; $\mathrm{CT}=$ clone trial; $\mathrm{YB}=$ yield block; $P$. = Populus; $\mathrm{D}=$ Populus deltoides Bartr.ex Marsh (eastern cottonwood); $\mathrm{N}=$ Populus nigra L (European black poplar).; $\mathrm{M}=$ Populus maximowiczii A. Henry (Japanese poplar); $T=$ Populus trichocarpa Torr. \& A. Gray (black cottonwood)

Keywords: hybrid poplars, Populus, age-age correlations, early selection, poplar breeding, clone selection

\section{Introduction}

Hybrid poplars (Populus spp.) are one of the most promising and tested dedicated crop sources for biomass feedstock in temperate climates. Poplar plantations have produced significant amounts of pulpwood for the paper industry in Minnesota and the Pacific Northwest, USA (Berguson et al., 2010), and are a focus of the nascent biofuel and bioproducts industry (US DOE, 2016). Achieving the national target of one billion dry tons of cellulosic biomass feedstock annually in the United States by 2030 will require producing more than 239 million dry tons each year from energy crops including hybrid poplars on agricultural soils (US DOE, 2016). The profitability of poplar plantations depends on many factors, but yield is a key determinant (Lazarus et al., 2015). Site selection and agronomic inputs can increase yield, and one of the most important inputs is the genetic composition of the planting material. The use of the most productive poplar clones has also been shown to reduce the environmental impact of biomass production (Bacenetti et al., 2016). The need for adapted, fast-growing, and disease-resistant poplar trees led us to establish the NRRI hybrid poplar genetics and breeding program. We have bred poplar families and clones and planted field tests annually in Minnesota and other areas of the USA for all but two years since 1996. Clones have been selected from these field tests. Our first generation improved clones exhibit up to a 70 percent increase in volume growth over commercially available genotypes (Nelson et al., 2018; Nelson, Berguson et al., 2019; Nelson, Meilan et al., 2019).

Even though the selection, breeding, and testing process for hybrid poplars is shorter than for most other tree species due to poplars' fast growth and amenability to cloning, up to 20 years are still required for one generation of genetic improvement in northern temperate climates, excluding parental testing and selection. The multi-step NRRI hybrid poplar improvement system, a sequential test process (Libby, 1987), is diagrammed in Figure 1. Any shortening and simplification of the 
genotype testing within the process would increase genetic gain per year and save time and money, providing additional efficiency. Alternatively, it may be necessary to increase the length of testing in some steps of the breeding process to achieve accurate selection for superior performance at full rotation.

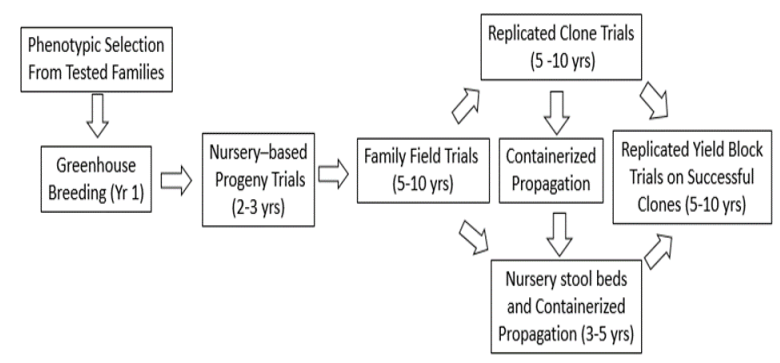

Figure 1

The NRRI (University of Minnesota Duluth - Natural Resources Research Institute) hybrid poplar breeding and testing process.

There are four potential avenues for increased efficiency with our genotype testing: 1 ) early selection; 2 ) elimination of one or more nursery-based progeny trial measurements; 3 ) providing clone performance estimates through FFTs, allowing the possible elimination of CTs; and 4) possible elimination of the final step, YB (monoclonal blocks of single clones meant to approximate commercial conditions), except for deriving biomass yield estimates. Vectors (quantities that have magnitude and direction) can provide this information in the form of: 1) Coefficient of Determination $\left(R^{2}\right)$ combined with information on the slope of the regression line (+ or -) from which $R^{2}$ is derived; 2 ) Spearman's Coefficient of Rank Correlation ( $\left.r_{s}\right)$; and 3) McFadden's Pseudo $\mathrm{R}^{2}$ for canker scoring correlations. We can calculate these vectors for age-age correlations of clone and family growth performance and for correlations of clone and family growth performance in different steps of the testing process. Our extensive databases of field sites in Minnesota for measuring survival, growth, and canker incidence and severity provide an opportunity to determine the earliest ages at which genotype performance can be reliably estimated and whether the testing steps can be simplified or compressed. Sites applicable to this study include nursery progeny trials (1 site), FFTs (6 sites), CTs (5 sites), and YBs (2 sites).

Age-age correlations are a common approach in genetic tree improvement programs for evaluating selection at less than full rotation age (early selection, indirect selection, juvenile-mature correlations) in many tree species (see Wu, 1999 and citations in White et al., 2007), including hybrid poplars. The cumulative nature of tree growth traits, under the assumption that annual increments are normally and independently distributed, results in tree size correlations between ages increasing monotonically with age even without any genetic correlation (Bisoffi, 1993). This mathematical fact contributes to the common observation that rotation performance of trees can be predicted at as early as one fourth of rotation age (Bisoffi and Gullberg, 1996).

Several studies document age-age correlations for poplars at traditional pulpwood production spacings. Wilkinson (1973), in a study of 350 older hybrid poplar clones in the northeastern USA, reported that selection at 1 to 4 years was inefficient for identifying the fastest-growing clones at 15 years. However, height and diameter at 9 years was highly correlated with the same variables at 15 years. Tsarev (1977) found that selection for poplar was effective at age $4-5$ years for an implied 12-year rotation. Foster (1986) reported a high genetic correlation between ages 4 and 7 for tree bole volume of Populus deltoides Bartr. ex Marsh (eastern cottonwood) in the lower Mississippi Valley USA, similar to age-age genetic and/or phenotypic correlations in Mohn and Randall (1971), Randall and Cooper (1973), and Ying and Bagley (1976) for P. deltoides, and Mohrdiek (1979) for Aigeiros $x$ Tacamahaca section poplar hybrids. For Populus deltoides and P. x euramericana (Populus deltoides $x$ Populus nigra; $D \times N$ ) in northern India, selection at age 3 or 4 was effective at identifying the best clones for a six-year rotation (Kumar and Singh, 2001). Chiba and Nagata (1972) found high phenotypic correlations within Populus maximowiczii Henry for height and diameter between years 3 and 7 for and for Melampsora rust susceptibility for year 1 versus year 7 . Kaczmarek et al. (2013) reported that for Populus trichocarpa Torr. \& A. Gray (black cottonwood) x Populus deltoides hybrids and pure Populus deltoides exhibited a high phenotypic correlation between survival at ages 1 and 10. Their results also indicated that selection for growth could be made at age 3 for a 10-year rotation, with only moderate to poorly performing clones changing rank between these ages. In a study of primarily Populus deltoides in Argentina, height and diameter growth at age 3 were significantly correlated with age 9 or 10 values (Ares, 2002), but there were large changes in individual clone rankings between these stand ages. First-year clone rankings for growth in poplars were not a good predictor of rankings at years 4 and 5 (Brown et al., 1996; Ghezehei et al., 2019). Ageage correlations have also been studied in poplar coppice rotations, e.g., Yaneza et al. (2019).

In summary, the existing literature for poplars supports effective selection between about 30 and 60 percent of rotation age for growth characters, with variation in age-age correlations likely due to site, clonal composition, region, and disease resistance. The effect of region on age-age correlations probably reflects climatic differences, e.g., the cumulative effects of recurrent killing frosts in more extreme northern continental climates such as that of Minnesota. This variability implies that it is informative and necessary to calculate age-age correlations for individual breeding programs with defined genotypes in specific regions.

Precise estimates of genetic correlations require extremely large experiments with offspring of many parents (White et al., 2007) and many ramets per genotype in a clonal experiment (e.g., Zhang et al., 2013), a condition that may not be met by the study reported here. Therefore, we employed phenotypic age-age correlations that are typically similar in size and magnitude to genetic correlations but tend to produce a more 
conservative estimate of optimum selection age (Gwaze et al., 2000).

All of the data analyzed here are from Minnesota USA, which has a continental northern temperate climate. Rotation length for hybrid poplars at pulpwood production spacings in Minnesota is approximately $10-12$ years, which frames our breeding process steps and age-age correlations. Crown closure occurs at about ages $3-5$ at the spacings in the FFTs, CTs, and $\mathrm{YBs}$ here, depending on the specific spacing. Variables evaluated in this study are survival, diameter breast height squared $\left(\mathrm{DBH}^{2}\right)$, and canker incidence and severity.

\section{Materials and Methods}

\section{The NRRI hybrid poplar breeding and testing process}

The NRRI Hybrid Poplar Breeding Process is a sequential breeding and testing system depicted in Figure 1. Phenotypic selection includes testing and recurrent selection of full-sib intra-specific families followed by inter-specific hybridization in a greenhouse to produce $F_{1}$ clones for testing and deployment. The rationale for the process is justified in Berguson et al. (2017). Our focus has evolved to emphasize Populus deltoides $x$ Populus nigra hybrids (aka P. $x$ canadensis known by the shorthand designations $\mathrm{D} x \mathrm{~N}$ and $\mathrm{DN}$ ) after prior field experimentation with a range of parental Populus species and hybrid combinations in the Midwest USA. The $P$. deltoides parents are primarily of Minnesota USA provenance. The system is based on a full rotation length of $10-12$ years in Minnesota and the other far northern tier of U.S. states, and $5-7$ years in the southern portion of the Midwest. In this paper, we refer to ages 9 and 10 as "full rotation" age. Details of greenhouse growing conditions and establishment and maintenance for the field plots providing data for this study are in the Materials and methods - Greenhouse breeding and Plantation establishment and maintenance sections, respectively.

\section{Phenotypic selection and collection of test families}

We select male and female parents for breeding from our field tests of pure species in Minnesota and from pure species genotypes, including non-native species, selected by cooperators outside Minnesota in Canada and the United States. Our internal program's family and clone selections of offspring of selected parents are based on growth and canker incidence and severity, typically at $3-5$ years stand age. Cankering is not a significant concern in P. deltoides in Minnesota.

Parent selections were based upon previous performance data from existing mature FFTs, from trees that had adequate floral branches of both seed and pollen candidate clones (on separate trees due to the dioecious nature of Populus spp.). Parents were also selected in older University of Minnesota existing collections and FFTs to fill breeding targets or matrix workplans. Vigorous one- and two-year-old floral-bearing branches, located in the upper crown of targeted parent trees, are collected and are preferred over older, gnarled branches of the lower crown. Flowering in existing genetic trials begins between the ages of six and eight years in eastern cottonwood (P. deltoides) and European black poplar (P. nigra). Floral branches were collected from sexually mature parent trees in January, when they were in a fully dormant state and floral buds were intact.

\section{Greenhouse breeding}

Roots were initiated on female branches while keeping the buds dormant and intact. These female cuttings with roots were then planted in pots in our breeding greenhouse, where flowers emerged. Male branches were forced to produce pollen in a separate greenhouse over two months in January and February. Female flowers were pollinated in isolation breeding hoods in the NRRI breeding greenhouse. Pollen and female flower forcing were both at a minimum temperature of 20 degrees C. Seed was collected when capsules dehisced and planted in germination flats. This seed was germinated in the greenhouse using an intermittent mist system. The germinated seedlings were transplanted to Spencer Lemaire ConeTainer tubes and grown over the summer and fall, moved outside for growth and development through the onset of dormancy, then stored in dark and cold greenhouse bays over the winter. The following spring, the seedlings were planted in the nursery for progeny trials. Details of the greenhouse breeding are in the online Supplementary Data.

\section{Nursery progeny trials (NPT)}

Between 25 and 75 seedlings (genotypes) from each full-sib family produced in the breeding were established at $0.3 \mathrm{~m}$ within row and $1.0 \mathrm{~m}$ between rows at the University of Minnesota North Central Research and Outreach Center (NCROC) site near Grand Rapids, MN. Individual clones were unreplicated. The goal was 75 seedlings per family, but we used the number available, with 25 seedlings as the minimum. These NPT plantings served as the cutting supply (stoolbeds, cutting orchard) for the FFTs, as well as an early-stage screening for climatic adaptability and disease resistance. Four measures of shoot growth were used to determine growth performance in the NPT as follows: All seedlings (genotypes) were measured for total height after one year of growth ( $\mathbf{r r} 1$ seedling ht), and some were measured after two years of growth (Yr 2 seedling ht). Most seedlings (those slated for stump sprouting) were cut to within $5 \mathrm{~cm}$ above ground in the winter after the first year of growth. These trees subsequently sprouted from the stump in year 2, and the terminal shoot was measured at the end of year 2 (Coppice 1). These same trees were then cut again to within $5 \mathrm{~cm}$ above ground in the winter after the second year of growth, subsequently sprouted from the stump in year 3, and the terminal shoot was measured at the end of year 3 (Coppice 2). As the NPT trials are unreplicated tests at the genotype level, the family mean of all four NPT growth measurements were analyzed for their relationship to family mean growth in FFTs, with the primary purpose being to choose the fastestgrowing full-sib families for the ensuing FFTs. However, plant material availability in the coppice stems (stools) was the primary underlying reason for inclusion in FFT establishment. Coppice 1 or 2 shoot growth are measured to gauge cutting 
supply for the FFTs, regardless of potential predictive value. Typically this procedure results in approximately the top $50 \%$ of families (based on family mean shoot growth rate) using the Coppice 1 and 2 results being selected for propagation in the greenhouse. Rooting success in the greenhouse is the ultimate criteria determining opportunity for planting in the field with balanced representation of families, clones, and ramets. A common target in FFTs is 30 full-sib families, with 20 individual clones per family and 5 ramets (replicates) of each clone. As reported in Berguson et al. (2017), this design allows us to evaluate sources of variance among families, within families, and within clones, all important values to better understand the potential of the overall breeding program to improve yield.

Shoots (whips) of clones within each selected family were harvested for cutting material. The selection of clones within family for harvesting was random, except that only clones that could produce the required number of cuttings for the field plot design were included, so that there was some bias toward faster-growing clones within each family, although the magnitude and significance of this effect is practically not quantifiable. The cutting production requirement, in addition to eliminating slower-growing families and clones, also eliminated clones that became diseased or were otherwise maladapted.

\section{Family field trials (FFT)}

Family Field Trials test full-sib families with seedling selections clonally replicated within each family. Dormant shoots (whips) harvested from the NPT in winter were stored below freezing and processed into 'mini' cuttings $7.6-10.1 \mathrm{~cm}$ in length, each cutting having at least two viable lateral vegetative buds and no terminal buds. These 'mini' cuttings were rooted in $107 \mathrm{ml}$ cells containing a coarse peat blend soil mix (Premier Tech Horticulture Pro-Mix HP Bio + MYCO) and grown for eight weeks in the greenhouse starting in late March, then moved outside for three weeks of environmental acclimation starting in early May. The six FFTs were then planted with these rooted cuttings in May/June at $3.0 \times 3.0$ spacing, with the exceptions being the Woelfel FFT at $2.4 \times 3.0 \mathrm{~m}$ and the MN Power FFT at $1.6 \times 1.6 \mathrm{~m}$.

\section{Clone trials (CT)}

The purpose of clone trials is to further evaluate the growth and disease performance of selected individual clones that performed well in the FFTs. Dormant shoots were harvested from the FFTs in winter. The remainder of the propagation and planting was the same as the FFT procedures. All spacing was $3.0 \times 3.0 \mathrm{~m}$. Growth parameter measured was $\mathrm{DBH}^{2}$ (tree diameter outside bark at $1.4 \mathrm{~m}$ squared). All clone trials included one or more commercial check clones ('NM6', 'DN5', 'DN2', ‘DN34' ('Eugenei')).

\section{Yield blocks (YB)}

Yield Blocks are considered the final stage of field testing and consist of clones set out in monoclonal blocks meant to approximate commercial conditions and to estimate biomass yield. Most of the clones in the YBs are those that have performed well in the FFTs and CTs. FFT and CT generally do not provide sound estimates of biomass yield per unit land because of wide variation in growth rate of adjoining trees in the plots. The number of selected clones included in a single $Y B$ in the trials used in this study varied from five clones for the LEA Grand Rapids YB to 22 for the Hansen YB. The LEA Grand Rapids YB included the commercial check clone, 'NM6' (Populus nigra $x$ Populus maximowiczii). Propagules for the YBs have varied in our process-some trials used unrooted cuttings, some rooted cuttings. In this study, the LEA Grand Rapids YB was established with $23 \mathrm{~cm}$ length unrooted cuttings, Hansen $Y B$ with $8 \mathrm{~cm}$ length containerized mini rooted cuttings. YB spacing was 3.0 x $3.0 \mathrm{~m}$ at Hansen and $2.4 \times 2.4 \mathrm{~m}$ at LEA Grand Rapids.

\section{Clone selection for FFT, CT, YB}

Clone selection for FFTs is described above.

Clones for CTs were selected from our Program's FFTs in Minnesota and from other sources within the region.

Selection of most clones for the CTs was based on diameters measured in our FFTs from ages $3-5$ years, along with canker scores and other categorical observations related to tree form. The FFTs have a family genetic structure, including clonally replicated full-sib individuals, and typically contain up to 900 genotypes. In addition to new clones selected from the FFTs, a small subset of those clones that performed well in earlier tests was included as a comparison to the new set of clones. Also, two commercial standards, 'DN2' (Populus deltoides $x$ Populus nigra) and 'NM6', were embedded within the clone trials.

The fastest-growing disease-resistant clones in the CTs with adequate cutting material available in stool beds were selected for the YB tests in most cases. However, the clones selected for the 2006 Hansen YB were selected from clone tests established before 2006, not from the 2006 Hansen CT. Other clones in the YBs were chosen to satisfy an industrial cooperator's request for evaluation of specific clones.

\section{Genotype identities}

The pedigrees of the full-sib families and clones and the number of replications in the trials are summarized in Tables 1 and 2. Detailed parentage of individual clones are in Tables $A 1-A 3$ in the online Supplementary Data. All families are full sib, produced through controlled pollinations. Taxa include: Populus deltoides (D); Populus nigra (N); and subsequent matings: $\mathrm{D} \times \mathrm{D}$ and/or $\mathrm{D} x \mathrm{~N}$ pedigrees; and additional full-sib families between P. deltoides $(\mathrm{D})$ x Populus maximowiczii $(\mathrm{M})$ to produce $\mathrm{D} x$ $\mathrm{M}$ pedigrees. No successful $\mathrm{N} x \mathrm{M}$ pedigrees were created by NRRI. The focus of our breeding program has evolved to emphasize the $\mathrm{D} x \mathrm{~N}$ cross. Crosses involving Populus maximowiczii and Populus trichocarpa are generally maladapted to midwestern USA conditions (Nelson et al., 2018). 
Table 1

Composition of Family Field Trials (FFT).

\begin{tabular}{|c|c|c|c|c|c|c|c|c|c|}
\hline Site & Year planted & $\begin{array}{l}\mathrm{CP} \text { breeding } \\
\text { population }\end{array}$ & $\begin{array}{l}\text { Number of full- } \\
\text { sib families }\end{array}$ & $\begin{array}{l}\text { Number of } \\
\text { clones }\end{array}$ & $\begin{array}{l}D \times D \\
\text { Number of } \\
\text { ramets }(n)\end{array}$ & $\begin{array}{l}D \times M \\
\text { Number of } \\
\text { ramets }(n)\end{array}$ & $\begin{array}{l}\mathrm{D} \times \mathrm{N} \\
\text { Number of } \\
\text { ramets }(\mathrm{n})\end{array}$ & $\begin{array}{l}\mathrm{D} \times \mathrm{T} \\
\text { Number of } \\
\text { ramets }(\mathrm{n})\end{array}$ & $\begin{array}{l}\text { Total } \\
\text { Number of } \\
\text { ramets }(\mathrm{n})\end{array}$ \\
\hline Woelfel & 2001 & 1998 & 36 & 910 & 1652 & 673 & 76 & 0 & 2401 \\
\hline Sturges 1 & 2002 & 1999 & 30 & 690 & 0 & 776 & 611 & 176 & 1563 \\
\hline Housman & 2004 & 1997,1999, 2002 & 26 & 475 & 0 & 546 & 478 & 147 & 1171 \\
\hline Schultz & 2007 & 2003,2004 & 25 & 219 & 0 & 0 & 564 & 51 & 615 \\
\hline Wanderscheid & 2008 & 2005,2006 & 36 & 371 & 881 & 0 & 712 & 75 & 1668 \\
\hline MN Power & 2015 & 2012 & 30 & 611 & 0 & 0 & 2898 & 0 & 2898 \\
\hline Totals over all sites & & & 183 & 3310 & 2533 & 1995 & 5339 & 449 & 10316 \\
\hline
\end{tabular}

$\mathrm{CP}=$ controlled breeding. $\mathrm{n}=$ observations (individual trees measured at 5 years).

Table 2

Composition of Clone Trials (CT) and Yield Blocks (YB).

\begin{tabular}{|c|c|c|c|c|c|c|c|c|}
\hline Site & Year planted & $\begin{array}{l}\text { P. deltoides/ } \\
\mathrm{D} \times \mathrm{D}\end{array}$ & $D \times M$ & $\mathrm{D} \times \mathrm{N}$ & P. nigra & $N \times M$ & Total clones & $\begin{array}{c}\text { Total } \\
\text { ramets }(\mathrm{n})\end{array}$ \\
\hline Hansen (CT) & 2006 & $(21 / 23) 44$ & 8 & 14 & 0 & 1 & 67 & 370 \\
\hline Schultz (CT & 2007 & $(16 / 33) 49$ & 4 & 10 & 0 & 0 & 63 & 340 \\
\hline Captain (CT) & 2009 & $(0 / 1) 1$ & 4 & 36 & 1 & 0 & 42 & 203 \\
\hline Hansmeyer (CT) & 2009 & $(0 / 1) 1$ & 4 & 37 & 1 & 0 & 43 & 198 \\
\hline Smith $(C T)$ & 2009 & $(0 / 0) 0$ & 4 & 38 & 1 & 0 & 43 & 229 \\
\hline Total unique clones in CT & & 94 & 16 & 62 & 1 & 1 & 174 & 1340 \\
\hline Hansen (YB) & 2006 & $(5 / 3) 8$ & 4 & 10 & 0 & 0 & 22 & 589 \\
\hline LEA GrRpds (YB) & 2007 & $(0 / 0) 0$ & 2 & 2 & 0 & 1 & 5 & 129 \\
\hline Totals (YB) & & 8 & 6 & 12 & 0 & 1 & 27 & 718 \\
\hline
\end{tabular}

\section{Site locations and descriptions}

The study sites are described in Table 3. All sites are in Minneso-

ta USA. The range in latitude and longitude of the sites is 46.0420 to 47.4452 and -93.4919 to -95.2378 , respectively. 
Table 3

Study site descriptions.

\begin{tabular}{|c|c|c|c|c|}
\hline Site & Captain CT & MN Power FFT & LEA Grand Rapids*YB & Hansen CT\&YB \\
\hline County (MN) & Todd & Itasca & Itasca & Todd \\
\hline Nearest town (MN) & Eagle Bend & Cohasset & Grand Rapids & Eagle Bend \\
\hline Latitude & 46.2096 & 47.2484 & 47.2435 & 46.1297 \\
\hline Longitude & -95.1225 & -93.7009 & -93.4919 & -95.058 \\
\hline Slope (\%) & $2-6$ & $0-10$ & $0-6$ & $2-6$ \\
\hline Soil texture & sandy loam & loamy very fine & fine sandy loam & sandy loam \\
\hline Soil pH & 6.2 & 6.1 & 5.3 & 6 \\
\hline Soil particulate organic matter (\%) & 1.88 & 0.52 & 10.42 & 2.43 \\
\hline Soil bulk density (g/cm3) & 1.49 & 1.59 & 1.36 & 1.61 \\
\hline Average high/low temperature (C) & 26.9/-19.8 & $26.8 / 19.3$ & $26.8 / 19.3$ & $24.2 /-17.1$ \\
\hline $\begin{array}{l}\text { Minnesota Crop Productivity Index (range } 0 \text { to } \\
\text { 100) }\end{array}$ & 88 & 45 & 90 & 85 \\
\hline Average precipitation - rainfall (mm) & 723 & 735 & 735 & 638 \\
\hline Site & Hansmeyer CT & Housman FFT & Schultz FFT\&CT & Smith CT \\
\hline County (MN) & Todd & Todd & Todd & Clearwater \\
\hline Nearest town (MN) & Browerville & Miltona & Clarissa & Bagley \\
\hline Latitude & 46.0420 & 46.0549 & 46.1952 & 47.4452 \\
\hline Longitude & -95.0336 & -95.1268 & -94.8613 & -95.2378 \\
\hline Slope\% & $2-6$ & $2-6$ & $2-6$ & $1-3$ \\
\hline Soil texture & sandy loam & sandy loam & sandy loam & very fine sandy loam \\
\hline Soil pH & 6 & 6.2 & 6 & 6.5 \\
\hline Soil particulate organic matter (\%) & 2.43 & 1.88 & 2.43 & 1.43 \\
\hline Soil bulk density (g/cm3) & 1.61 & 1.49 & 1.61 & 1.46 \\
\hline Average high/low temperature (C) & $24.2 /-17.1$ & $24.2 /-17.1$ & 1.4972067 & $26.1 /-20.5$ \\
\hline $\begin{array}{l}\text { Minnesota Crop Productivity Index (range } 0 \text { to } \\
\text { 100) }\end{array}$ & 85 & 88 & 85 & 90 \\
\hline Average precipitation - rainfall (mm) & 638 & 638 & 769 & 648 \\
\hline Site & Sturges FFT & Wanderscheid FFT & Woelfel FFT & \\
\hline County (MN) & Otter Tail & Todd & Todd & \\
\hline Nearest town (MN) & Rose City & Clarissa & Bertha & \\
\hline Latitude & 46.1352 & 46.1129 & 46.2657 & \\
\hline Longitude & -95.1653 & -95.0118 & -95.1447 & \\
\hline Slope\% & $2-6$ & $2-6$ & $2-6$ & \\
\hline Soil texture & sandy loam & sandy loam & sandy loam & \\
\hline Soil pH & 6.3 & 6.5 & 6.3 & \\
\hline Soil particulate organic matter (\%) & 2.2 & 3 & 2.2 & \\
\hline Soil bulk density (g/cm3) & 1.5 & 1.48 & 1.5 & \\
\hline Average high/low temperature (C) & $24.2 /-17.1$ & 1.4972067 & 26.9/-19.8 & \\
\hline $\begin{array}{l}\text { Minnesota Crop Productivity Index (range } 0 \text { to } \\
\text { 100) }\end{array}$ & 88 & 85 & 88 & \\
\hline Average precipitation - rainfall (mm) & 638 & 769 & 723 & \\
\hline
\end{tabular}

- *LEA Grand Rapids data also applies to the nursery progeny tests (NPT), which are located on the same experimental farm (an insignificant difference in latitude and longitude).

- Soil data from https://websoilsurvey.sc.egov.usda.gov/App/HomePage.htm

- Climate data from https://www.usclimatedata.com/ U.S. Climate Data, three-decade (1981-2010) averages (National Centers for Environmental Information, NOAA).

Crop Productivity Index from https://websoilsurvey.sc.egov.usda.gov/App/HomePage.htm 


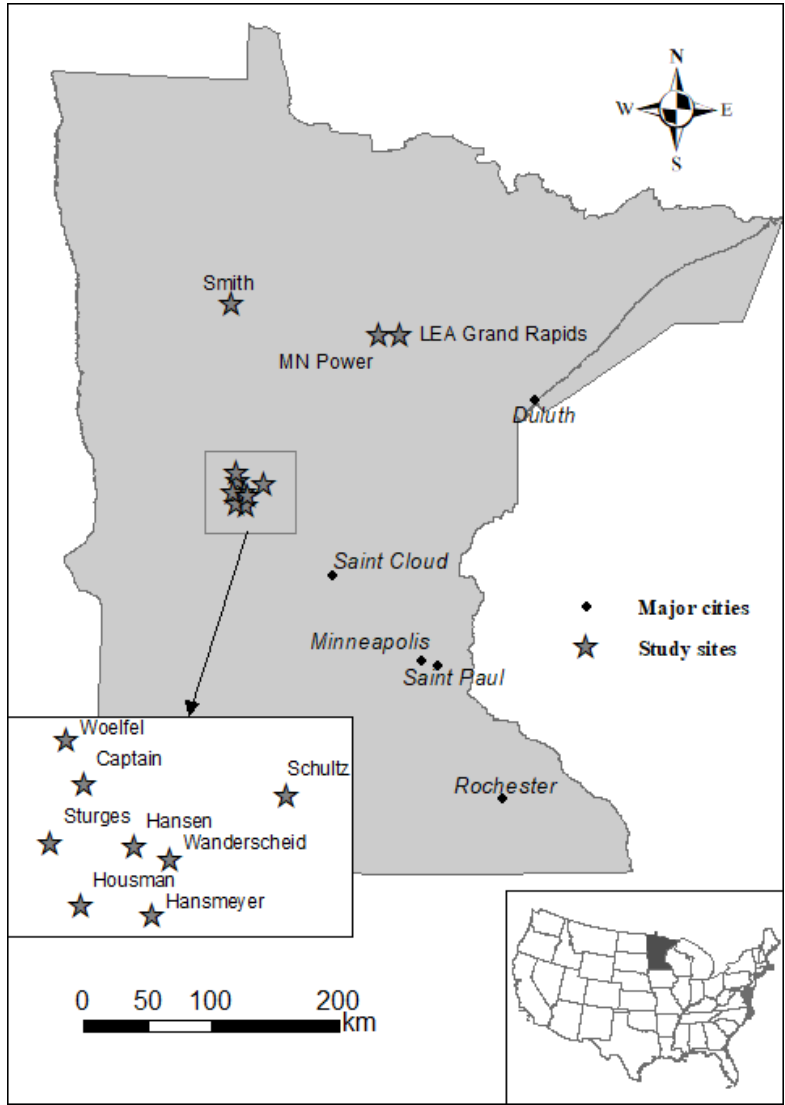

Figure 2

Map of study sites.

\section{Field trial design}

The NPT was unreplicated. FFTs, CTs, and YBs were randomized complete blocks. All FFTs were single-tree plots, with 3 replications (Housman, Schultz, Sturges 1, Woelfel) or 5 replications (Wanderscheid, MN Power) of from 20 to 36 families. CTs were all single-tree plots with 6 replications of up to 67 clones. The YB tests blocks each had 9 interior trees that were measured, surrounded by a two-row buffer of the same clone, with three replications (blocks) of each clone, resulting in a maximum of 27 tree measurements per clone in each YB. Using this design, tree growth is more representative of growth in large-scale commercial plantations than it is in FFTs and CTs. YB Hansen had 3 replications of 22 clones, and YB LEA Grand Rapids had 3 replications of 5 clones.

\section{Plantation establishment and maintenance}

The sites were prepared and planted in the spring, sprayed with glyphosate at 3.51 liters of $41.0 \%$ active ingredient per hectare and tilled. Containerized plants were hand planted on pre-marked fields at pulpwood production spacings described above. The sites were immediately sprayed with the pre-emergent chemical Scepter 70DG (Imazaquin) at $292 \mathrm{ml}$ of $70.0 \%$ active ingredient per hectare. Further weed competition was effectively controlled through mechanical means during the first three growing seasons. Sites were not irrigated. Planting year for the sites is given in Tables 1 and 2. Survival measured at 2 - 4 years ranged between $76 \%$ and $99 \%$ for FFTs, CTs, and YBs.

\section{Growth measurement}

For the NPTs, shoot length was measured in four different ways as described above. For the FFTs, CTs, and YBs, diameter at 1.4 $\mathrm{m}$ above ground (breast height), $\mathrm{DBH}$, was measured on each tree. The growth variable analyzed for FFTs, CTs, and YBs was $\mathrm{DBH}^{2}$, as this metric relates directly to cross-section area of the tree bole (basal area) and tree volume (Krinard, 1988). We also used cumulative basal area for each 9-tree plot in the YBs as a metric for YB growth, a metric that is affected by survival.

\section{Pathogen assessments}

The primary plant pathogen of concern for hybrid poplar culture in Minnesota and elsewhere in the eastern half of North America has been a stem- and branch-cankering disease caused by the fungal pathogen Sphaerulina musiva (Peck) Quaedvlieg, Verkley \& Crous, formerly known as Septoria musiva. We see canker development on shoots as early as the first year in tightly spaced nursery stoolbeds, but more commonly by the third year of growth in the wider-spaced field trials and plantations.

Cankers or lesions of unknown cause were observed and scored categorically in the NPTs, CTs, and FFTs in the autumn of each year. Cankers were not scored for the YBs, but obvious canker damage was noted. Following natural leaf senescence and leaf fall, incidence of cankers or lesions on the branches and boles of each tree was rated according to a three-class scoring system: 0 = cankers absent; 1 = cankers present but rare; and 2 = cankers present with multiple areas of sunken, necrotic tissue on main boles and/or branches. All canker scoring was done by one individual, an experienced poplar geneticist and breeder, to reduce variability, as the canker scoring system involves some subjectivity.

\section{Statistical analysis}

Vectors chosen for the analysis of growth are the Coefficient of Determination $\left(R^{2}\right)$ for linear regression and Spearman's Coefficient of Rank Correlation $\left(r_{s}\right)$. McFadden's Pseudo $R^{2}$ was calculated for the categorical (ordinal) canker data fitted to the nominal logistic model, due to the non-normality of the canker score data. All age-age correlations were based on individual clone values. The linear regression line for tree size from earlier to later ages always has a positive slope, as trees do not get smaller with age. The logistic regression of canker score for age-age correlations would be expected to have a positive slope, as trees rarely have less cankering at older ages, except in the infrequent case of cankers that heal over. McFadden's Pseudo $\mathrm{R}^{2}$ was only used for the age-age correlations for canker score in CTs because canker scoring only was done in CTs. Statistical analysis was performed in JMP Pro 14 and R 3.5.1. Replication was identical for each clone at the beginning of each field trial but varied from clone to clone after year 1 due to differential survival. Therefore, $\mathrm{DBH}^{2}$ was averaged for each clone 
within each site. The data distribution of mean $\mathrm{DBH}^{2}$ was plotted and was close to a normal distribution for most sites; therefore, no data transformation was applied to the growth data. Age-age correlations were FFT: ages 3, 4, and 5; CT: ages 3, 4, 5 , 9, 10; and YB: ages 3, 4, 5, 9, 10. For correlation of clones between breeding and testing process steps ( NPT to FFT, FFT to $\mathrm{CT}, \mathrm{CT}$ to $\mathrm{YB}$ ), $\mathrm{DBH}^{2}$ at 4 or 5 years was used for $\mathrm{FFT}$, and $\mathrm{DBH}^{2}$ at ages $3,4,5,9$, and 10 for CT and YB. The primary NPT to FFT correlations were family mean to family mean, although we did test genotype-to-clone regressions for one site (MN Power), where family mean to family mean correlations were non-significant. FFT to $\mathrm{CT}$ correlations and $\mathrm{CT}$ to $\mathrm{YB}$ correlations were clone to clone only. Clones were ranked by $\mathrm{DBH}^{2}$ for each CT. Clonal variance and repeatability and environmental variance in FFT and CT were calculated according to equations 1 and 2 in Baltunis and Brawner (2010), based on a mixed model with replication as a fixed factor and clone as a random factor.
Correlations of $\mathrm{DBH}^{2}$ and clone rank with age at different stand ages are in Tables 4, 5, and 6 for FFT, CT, and YB, respectively. The pattern of individual clone ranks at 3 and 5 years versus age 9 or 10 is illustrated in Table 7. The canker scores by site, stand age, and taxon type in the clone trials are in Figure 3. Correlations (McFadden's Pseudo $\mathrm{R}^{2}$ ) of canker scores between stand ages in the clone trials are in Table 8, and the pattern of canker score changes in CTs with stand age for taxon types over all sites is illustrated in Figure 3.

As shown in Table 4 for FFTs, the correlations between $\mathrm{DBH}^{2}$ at ages 3 and 4 versus $\mathrm{DBH}^{2}$ at age 5 were highly significant on all sites, higher for age 4 versus age 5 than for age 3 versus 5 . The Spearman's rank correlations $\left(r_{s}\right)$ (Table 4 ) were also all highly significant for ages 3 and 4 versus age 5 , again higher for age 4 vs age 5 than for age 3 vs age 5 .

\section{Results}

\section{Age-age correlations}

The range of overall mean $\mathrm{DBH}^{2}\left(\mathrm{~cm}^{2}\right)$ at age 5 for sites was: FFT 44.62 - 108.57 (excluding the MN Power site, which was not measured at age 5); CT 53.09 - 112.21; YB 93.29 - 117.85. Detailed $\mathrm{DBH}^{2}$ data for the FFTs, CTs, and YBs for all sites, species types, and ages are in Tables A5, A6, A7 of the online Supplementary Data. There was variation in spacing between different sites (see above), so the $\mathrm{DBH}^{2}$ ranges cannot be directly compared in all cases.

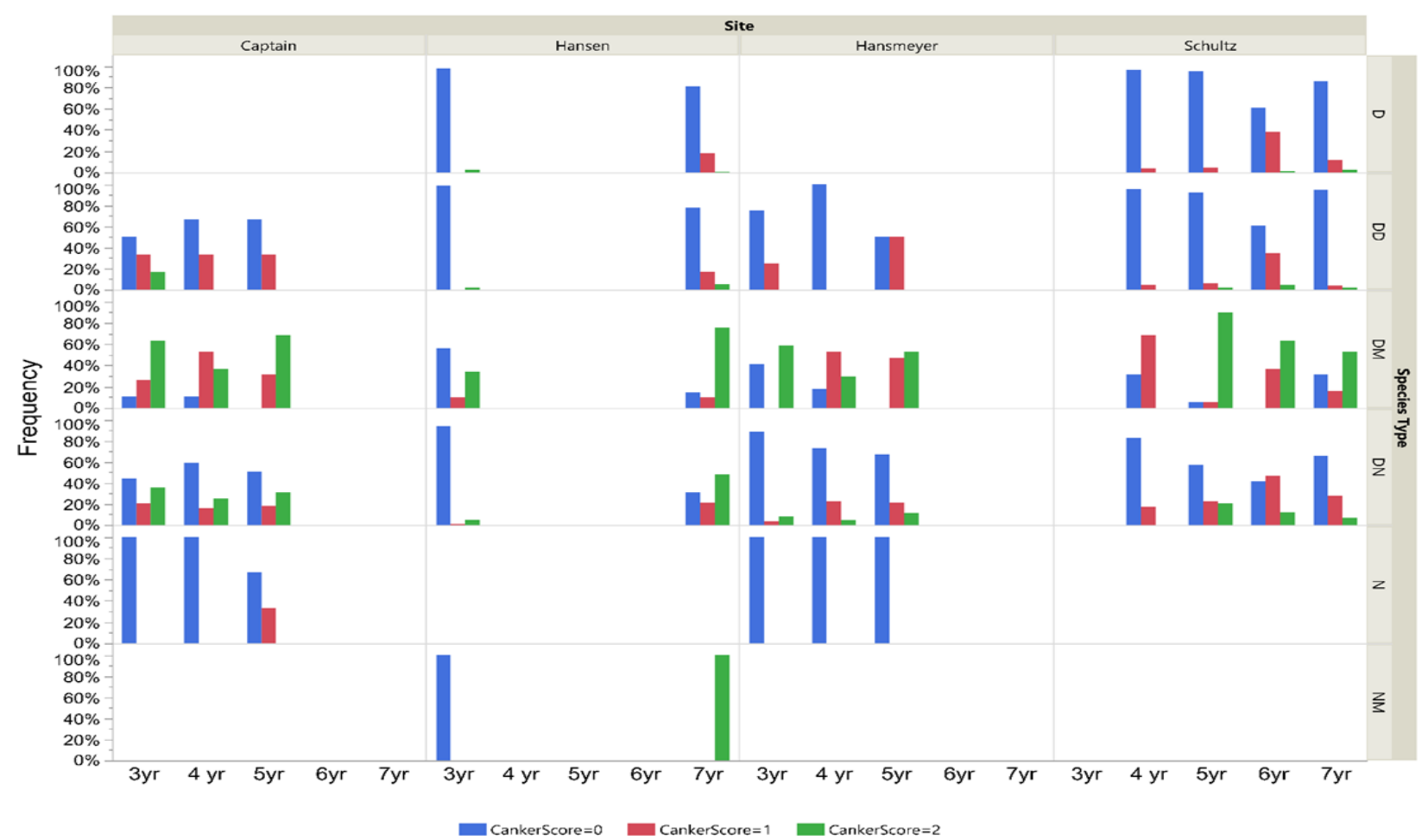

Figure 3

The frequency percentage of canker scores for each site, species type and age in the clone trials. $0=$ cankers absent; $1=$ cankers present but rare; and 2 = cankers present with multiple areas of sunken, necrotic tissue on main boles and/or branches. 
Table 4

Family Field Trials - The linear regression fit $\mathrm{R}^{2}$ and Spearman's correlation coefficients for $\mathrm{DBH}^{2}$ between different years.

\begin{tabular}{|c|c|c|c|c|c|c|}
\hline \multirow[t]{2}{*}{ Age } & \multicolumn{3}{|c|}{$\mathrm{R}^{2}$} & \multicolumn{3}{|c|}{ Spearman's correlation coefficients } \\
\hline & 3 & 4 & 5 & 3 & 4 & 5 \\
\hline \multicolumn{7}{|c|}{ Woelfel ( $\mathrm{n}=910$ individual trees) } \\
\hline 3 & 1 & 0.874 & 0.692 & 1 & 0.932 & 0.817 \\
\hline 4 & 0.874 & 1 & 0.875 & 0.932 & 1 & 0.930 \\
\hline 5 & 0.692 & 0.875 & 1 & 0.817 & 0.930 & 1 \\
\hline \multicolumn{7}{|c|}{ Sturges 1 ( $\mathrm{n}=690$ individual trees) } \\
\hline 3 & 1 & 0.763 & 0.577 & 1 & 0.882 & 0.778 \\
\hline 4 & 0.763 & 1 & 0.874 & 0.882 & 1 & 0.933 \\
\hline 5 & 0.577 & 0.874 & 1 & 0.778 & 0.933 & 1 \\
\hline \multicolumn{7}{|c|}{ Housman ( $\mathrm{n}=475$ individual trees) } \\
\hline 3 & 1 & 0.858 & 0.635 & 1 & 0.935 & 0.809 \\
\hline 4 & 0.858 & 1 & 0.860 & 0.935 & 1 & 0.920 \\
\hline 5 & 0.635 & 0.860 & 1 & 0.809 & 0.920 & 1 \\
\hline \multicolumn{7}{|c|}{ Schultz ( $n=219$ individual trees) } \\
\hline 3 & 1 & 0.881 & 0.691 & 1 & 0.937 & 0.840 \\
\hline 4 & 0.881 & 1 & 0.876 & 0.937 & 1 & 0.942 \\
\hline 5 & 0.691 & 0.876 & 1 & 0.840 & 0.942 & 1 \\
\hline \multicolumn{7}{|c|}{ Wanderscheid ( $\mathrm{n}=371$ individual trees) } \\
\hline 3 & 1 & 0.751 & 0.663 & 1 & 0.863 & 0.816 \\
\hline 4 & 0.751 & 1 & 0.954 & 0.863 & 1 & 0.972 \\
\hline 5 & 0.663 & 0.954 & 1 & 0.816 & 0.972 & 1 \\
\hline
\end{tabular}

Table 5 enumerates the age-age correlations in CTs, with the correlation between earlier ages and age 9 or 10 being the most important. Age 10 is the approximate lower bound of rotation age in Minnesota. All age-age correlations were significant at the $\mathrm{p}<0.05$ level, age 5 providing a much better correlation with age 10 for $\mathrm{DBH}^{2}$ and clone rank than ages 3 and 4 , i.e., half-rotation seems to provide a good estimate of growth and rank results at full rotation in the CTs. Even though the significant Spearman's Coefficients indicated no rank change with age in the clone trials, there was some variability in ranking for $\mathrm{DBH}^{2}$ of individual clones with age on the different sites (Table 7). Clone rank for each genotype in the CTs at different ages are in Table A4 in the online Supplementary Data. An average of 42 $\%$ of the 10 top-ranked clones at age 9 or 10 were in the top 10 clones at age $3,56 \%$ at age 5 . This varied by site (Table 7 ). 
Table 5

Clone Trials - The linear regression fit $\mathrm{R}^{2}$ and Spearman's correlation coefficients for $\mathrm{DBH}^{2}$ between different years for clone trials. All coefficients are from the significant linear fits or correlations. All coefficients are significant at $\mathrm{p}<0.05$. Blank cells are those without pairwise data.

\begin{tabular}{|c|c|c|c|c|c|c|c|c|c|c|}
\hline \multirow[t]{2}{*}{ Age } & \multicolumn{5}{|c|}{$\mathrm{R}^{2}$} & \multicolumn{5}{|c|}{ Spearman correlation coefficients } \\
\hline & 3 & 4 & 5 & 9 & 10 & 3 & 4 & 5 & 9 & 10 \\
\hline \multicolumn{11}{|c|}{ Hansen ( $\mathrm{n}=67$ clones) } \\
\hline 3 & 1 & 0.830 & 0.695 & 0.260 & & 1 & 0.873 & 0.800 & 0.485 & \\
\hline 4 & 0.830 & 1 & 0.882 & 0.408 & & 0.873 & 1 & 0.921 & 0.606 & \\
\hline 5 & 0.695 & 0.882 & 1 & 0.600 & & 0.800 & 0.921 & 1 & 0.728 & \\
\hline 9 & 0.260 & 0.408 & 0.600 & 1 & & 0.485 & 0.606 & 0.728 & 1 & \\
\hline \multicolumn{11}{|l|}{10} \\
\hline \multicolumn{11}{|c|}{ Schultz n=63 clones) } \\
\hline 3 & 1 & 0.832 & 0.711 & & 0.316 & 1 & 0.905 & 0.843 & & 0.577 \\
\hline 4 & 0.832 & 1 & 0.898 & & 0.491 & 0.905 & 1 & 0.958 & & 0.728 \\
\hline 5 & 0.711 & 0.898 & 1 & & 0.720 & 0.843 & 0.958 & 1 & & 0.838 \\
\hline \multicolumn{11}{|l|}{9} \\
\hline 10 & 0.316 & 0.491 & 0.720 & & 1 & 0.577 & 0.728 & 0.838 & & 1 \\
\hline \multicolumn{11}{|c|}{ Captain ( $\mathrm{n}=42$ clones) } \\
\hline 3 & 1 & 0.840 & 0.673 & & 0.266 & 1 & 0.900 & 0.795 & & 0.479 \\
\hline 4 & 0.840 & 1 & 0.913 & & 0.559 & 0.900 & 1 & 0.940 & & 0.695 \\
\hline 5 & 0.673 & 0.913 & 1 & & 0.708 & 0.795 & 0.940 & 1 & & 0.828 \\
\hline \multicolumn{11}{|l|}{9} \\
\hline 10 & 0.266 & 0.559 & 0.708 & & 1 & 0.479 & 0.695 & 0.828 & & 1 \\
\hline \multicolumn{11}{|c|}{ Hansmeyer ( $\mathrm{n}=43$ clones) } \\
\hline 3 & 1 & 0.937 & 0.888 & & 0.364 & 1 & 0.959 & 0.946 & & 0.611 \\
\hline 4 & 0.937 & 1 & 0.953 & & 0.432 & 0.959 & 1 & 0.981 & & 0.675 \\
\hline 5 & 0.888 & 0.953 & 1 & & 0.601 & 0.946 & 0.981 & 1 & & 0.742 \\
\hline \multicolumn{11}{|l|}{9} \\
\hline 10 & 0.364 & 0.432 & 0.601 & & 1 & 0.611 & 0.675 & 0.742 & & 1 \\
\hline \multicolumn{11}{|c|}{ Smith ( $\mathrm{n}=43$ clones) } \\
\hline 3 & 1 & 0.676 & 0.567 & & 0.193 & 1 & 0.730 & 0.603 & & 0.361 \\
\hline 4 & 0.676 & 1 & 0.911 & & 0.269 & 0.730 & 1 & 0.936 & & 0.430 \\
\hline 5 & 0.567 & 0.911 & 1 & & 0.390 & 0.603 & 0.936 & 1 & & 0.561 \\
\hline \multicolumn{11}{|l|}{9} \\
\hline 10 & 0.193 & 0.269 & 0.390 & & 1 & 0.361 & 0.430 & 0.561 & & 1 \\
\hline
\end{tabular}

Yield Block age-age correlation results (Table 6) were different and more variable than for FFTs and CTs. For absolute $\mathrm{DBH}^{2}$ and $\mathrm{DBH}^{2}$ rank $\left(r_{s}\right)$, ages 3,4 , and 5 were generally poorly correlated with absolute $\mathrm{DBH}^{2}$ at age 9 or 10 . We also analyzed age-age correlations in the Hansen YB using clone average cumulative basal area, which gave the same pattern as the $\mathrm{DBH}^{2}$ metric, with slightly lower $\mathrm{R}^{2}$ and Spearman's Coefficients (data not shown).

Table 6

Yield Blocks - The linear regression fit $\mathrm{R}^{2}$ and Spearman's correlation coefficients for clone mean $\mathrm{DBH}^{2}$ between different years. All coefficients are from the significant $(p<0.05)$ linear fits or correlations. Insignificant fits are labelled $n s$. Blank cells are those without pairwise data.

\begin{tabular}{|c|c|c|c|c|c|c|c|c|c|c|}
\hline \multirow[t]{2}{*}{ Age } & \multicolumn{5}{|c|}{$\mathrm{R}^{2}$} & \multicolumn{5}{|c|}{ Spearman correlation coefficients } \\
\hline & 3 & 4 & 5 & 9 & 10 & 3 & 4 & 5 & 9 & 10 \\
\hline \multicolumn{11}{|c|}{ Hansen ( $\mathrm{n}=22$ clones) } \\
\hline 3 & 1 & 0.889 & 0.584 & ns & & 1 & 0.939 & 0.785 & ns & \\
\hline 4 & 0.889 & 1 & 0.816 & ns & & 0.939 & 1 & 0.905 & ns & \\
\hline 5 & 0.584 & 0.816 & 1 & 0.218 & & 0.785 & 0.905 & 1 & 0.481 & \\
\hline 9 & ns & ns & 0.218 & & & ns & ns & 0.481 & 1 & \\
\hline \multicolumn{11}{|l|}{10} \\
\hline \multicolumn{11}{|c|}{ LEA Grand Rapids ( $\mathrm{n}=5$ clones) } \\
\hline \multicolumn{11}{|l|}{3} \\
\hline 4 & & 1 & 0.990 & & ns & & 1 & 1 & & ns \\
\hline 5 & & 0.990 & 1 & & ns & & 1 & 1 & & ns \\
\hline \multicolumn{11}{|l|}{9} \\
\hline 10 & & ns & ns & & 1 & & ns & ns & & 1 \\
\hline
\end{tabular}


Table 7

Overlap in ranking for $\mathrm{DBH}^{2}$ of individual clones at different ages in Clone Trials. All sites except Hansen are versus age 10; Hansen is versus age 9 . Top ten clones equal $81^{\text {st }}$ percentile for all sites combined.

\begin{tabular}{lcc}
\hline Site & \% of top-ranked 10 clones in year 9 or 10 at year 3 & \% of top-ranked 10 clones in year 9 or 10 at year 5 \\
\hline Hansen & $20 \%$ & $40 \%$ \\
Schultz & $40 \%$ & $80 \%$ \\
Captain & $60 \%$ & $60 \%$ \\
Hansmeyer & $50 \%$ & $50 \%$ \\
Smith & $40 \%$ & $50 \%$ \\
Average for 5 sites & $42 \%$ & $56 \%$ \\
\hline
\end{tabular}

Age-age correlations for canker score in CTs (Table 8) were significant at the $\mathrm{p}<0.5$ level for all age pairings from age 3 to age 7 , but the McFadden's pseudo $\mathrm{R}^{2}$ values were all low, i.e., cankering at older ages was not well predicted by canker scores earlier in the rotation. The square root of all McFadden's pseudo $\mathrm{R}^{2}$ values were positive as expected, i.e., cankering proceeds from lighter to heavier with age. The canker score pattern varied with taxon (species type) and site in the CTs (Fig. 3). See also Figure $\mathrm{A} 1$ in online Supplementary Data. The $\mathrm{D} x \mathrm{M}$ and $\mathrm{N} \times \mathrm{M}$ crosses were ultimately most cankered; $N, D$, and $D \times D$ the least; and $\mathrm{D} \times \mathrm{N}$ intermediate.

Table 8

Clone Trials - The McFadden's pseudo $\mathrm{R}^{2}$ from the nominal logistic model fit for Canker Scores between different years. All values are from significant $(\mathrm{p}<0.05)$ fits. Blank cells are those without pairwise data.

\begin{tabular}{|c|c|c|c|c|c|}
\hline Age & $3 \mathrm{Yr}$ & $4 \mathrm{Yr}$ & $5 \mathrm{Yr}$ & $6 \mathrm{Yr}$ & $7 Y r$ \\
\hline \multicolumn{6}{|c|}{ Hansen ( $n=370$ individual trees) } \\
\hline $3 Y r$ & & & & & 0.061 \\
\hline $7 \mathrm{Yr}$ & 0.061 & & & & 1 \\
\hline \multicolumn{6}{|c|}{ Schultz ( $\mathrm{n}=340$ individual trees) } \\
\hline $4 \mathrm{Yr}$ & & 1 & 0.179 & 0.097 & 0.044 \\
\hline $5 Y r$ & & 0.179 & 1 & 0.146 & 0.175 \\
\hline $6 \mathrm{Yr}$ & & 0.097 & 0.146 & 1 & 0.184 \\
\hline $7 \mathrm{Yr}$ & & 0.044 & 0.175 & 0.184 & 1 \\
\hline \multicolumn{6}{|c|}{ Captain ( $n=203$ individual trees) } \\
\hline $3 Y r$ & 1 & 0.280 & 0.231 & & \\
\hline $4 \mathrm{Yr}$ & 0.280 & 1 & 0.284 & & \\
\hline $5 Y r$ & 0.231 & 0.284 & 1 & & \\
\hline \multicolumn{6}{|c|}{ Hansmeyer ( $n=198$ individual trees) } \\
\hline $3 Y r$ & 1 & 0.116 & 0.074 & & \\
\hline $4 \mathrm{Yr}$ & 0.116 & 1 & 0.089 & & \\
\hline $5 Y r$ & 0.074 & 0.089 & 1 & & \\
\hline
\end{tabular}

\section{Correlations between breeding and testing process steps}

Correlations between NPT growth measures and FFT family mean growth and rank are in Table 9. All are family mean to family mean correlations, as the focus of the NPT is to select families for the FFT. All correlations for the MN Power site were non-significant. All NPT growth measures were significantly correlated with family mean $\mathrm{DBH}^{2}$ and rank at 4 and 5 years stand age in the Woelfel FFT. The highest correlation at the Woelfel site, (Spearman's coefficient $=r_{s^{\prime}}$ NPT Year 1 Seedling $\mathrm{Ht}$. vs FFT family rank) was 0.589 , a moderate correlation explaining $34 \%$ of the variation in family mean rank. The highest correlation between NPT growth measures and FFT $\mathrm{DBH}^{2}$ (Woelfel, $\mathrm{R}^{2}$, NPT Year 1 Seedling Ht. vs FFT DBH ${ }^{2}$ ) explained 
$32.5 \%$ of total variation in family mean $\mathrm{DBH}^{2}$. No other $\mathrm{R}^{2}$ or $\mathrm{r}_{\mathrm{s}}$ for either site came close to this correlation (Table 9). The nonsignificant fits for the MN Power site may be partially due to the smaller population size at that site than at Woelfel ( $N=62$ vs $N$ $=30$ ). Using the sum of the NPT growth measures as a predictor did not improve the correlations over using the single growth measure that returned the highest correlation (Table 9). When raw (genotype to clone) data, instead of family mean to family mean, were used for the regressions for NPT growth measures vs the MN Power site growth data, all regressions were significant at the $\mathrm{p}<0.05$ level (data not shown). This indicates that the NPT growth measures are effective selection criteria for clone growth in the FFTs but are not as effective for selecting families for the FFTs at the population sizes in this study. As explained under Methods, the main purpose of NPT growth measures is to select the best families to proceed into FFTs.

Table 9

The linear regression fit $\mathrm{R}^{2}$ and Spearman's correlation coefficients between NPT growth measures and FFT Dbh², family mean to family mean. NPT sum is the sum of shoot lengths (height growth) for all four NPT growth measures. All fits for the MN power site (italics) are statistically non-significant, but all fits for the Woelfel site (bold) are statistically significant $(\mathrm{p}<0.5)$ but relatively weak, explaining less than $35 \%$ of the variation. Blank cells are those without pairwise data.

\begin{tabular}{|c|c|c|c|c|}
\hline \multirow[b]{2}{*}{ NPT } & \multicolumn{2}{|c|}{ MN Power site, vs yr4Dbh ${ }^{2}$ ( $=30$ observations) } & \multicolumn{2}{|c|}{ Woelfel site, vs Yr5Dbh ${ }^{2}$ ( $=62$ observations) } \\
\hline & $\mathrm{R}^{2}$ & Spearman's correlation coef & $\mathrm{R}^{2}$ & Spearman's correlation coef \\
\hline NPT Year 1 seedling ht. & 0.002 & 0.066 & 0.325 & 0.589 \\
\hline NPT Year 2 seedling ht. & & & 0.096 & 0.320 \\
\hline NPT Coppice 1 & 0.007 & 0.049 & 0.144 & 0.361 \\
\hline NPT Coppice 2 & 0.042 & 0.126 & & \\
\hline NPT sum & 0.022 & 0.091 & 0.153 & 0.411 \\
\hline
\end{tabular}

Scatterplots of FFT DBH ${ }^{2}$ versus NPT shoot length growth measures (Figs. A2, A3 in online Supplementary Data) indicated a positive slope for the regression line for significant $R^{2}$; viz, faster growth in the NPT tends to indicate faster growth in the FFTs. Scatterplot matrices between NPT growth measures (Figs. A2, A3 in online Supplementary Data) showed a positive relationship, e.g., seedling heights were positively and closely related to coppice shoot lengths in the NPTs. The correlation vectors for growth and rank were positive as expected.

Regressing clone values in the CTs on clone values in the FFTs at ages 4 and 5 years for the 6 FFTs in Table 1 and the $5 \mathrm{CT}$ in Table 2 for growth rate $\left(\mathrm{DBH}^{2}\right)$ (actual growth rate $=\mathrm{R}^{2}$, clone rank for growth rate $=r_{s}$ ) were made to test whether clone performance in FFTs could be used to predict clone performance in CTs. Almost all $R^{2}$ and $r_{s}$ were non significant at the $p<0.05$ level (data not shown). Out of 36 such linear regressions for actual growth, only 3 had a significant $\mathrm{R}^{2}$, the largest explaining $30 \%$ of the variation in CT clone means. Only two $r_{s}$ out of 36 for rank correlations were significant $\left(r_{s}=0.543\right.$,
0.829). Genetic variances and clonal repeatabilities for FFTs and CTs are in Table 10. 
Table 10

Genetic variance among clones and clonal repeatabilities in FFT and CT. All repeatabilities are significant at the $\mathrm{p}<0.0001$ level, computed from standard errors of repeatability (data not shown).

\begin{tabular}{|c|c|c|c|c|c|c|}
\hline Test Type & Site & $\begin{array}{c}\text { Number of obser- } \\
\text { vations }\end{array}$ & $\begin{array}{l}\text { Number of } \\
\text { clones }\end{array}$ & $\begin{array}{l}\text { Genetic variance } \\
\text { among clones }\end{array}$ & Residual variance & Repeatability \\
\hline & Captain & 203 & 42 & 531.27 & 551.85 & 0.490 \\
\hline & Hansen & 370 & 67 & 464.41 & 720.29 & 0.392 \\
\hline \multirow[t]{3}{*}{$\mathrm{CTs}$} & Hansmeyer & 198 & 43 & 558.85 & 673.84 & 0.453 \\
\hline & Schultz & 340 & 63 & 583.90 & 1131.25 & 0.340 \\
\hline & Smith & 229 & 43 & 78.25 & 351.89 & 0.182 \\
\hline Ave per & & & & 443.34 & 685.82 & 0.371 \\
\hline \multicolumn{7}{|l|}{ CT site } \\
\hline & Housman & 1144 & 475 & 211.62 & 728.68 & 0.225 \\
\hline & Schultz & 615 & 219 & 1442.28 & 1012.02 & 0.588 \\
\hline \multirow[t]{3}{*}{ FFTs } & Sturges1 & 1433 & 690 & 504.40 & 441.98 & 0.533 \\
\hline & Wanderscheid & 1666 & 371 & 591.00 & 592.61 & 0.499 \\
\hline & Woelfel & 2371 & 910 & 469.76 & 318.49 & 0.596 \\
\hline Ave per & & & & 643.81 & 618.76 & 0.488 \\
\hline FFT site & & & & & & \\
\hline
\end{tabular}

Regressions for clone means in CTs versus YBs for the Hansen $C T$ and $Y B s$ are in Table 11. $R^{2}$ and Spearman's coefficient were significant at the $\mathrm{p}<0.05$ for age 3,4 , and 5 comparisons. However, the correlations between age 5 in the CTs and age 9 in the $\mathrm{YB}$ were non-significant. $\mathrm{DBH}^{2}$ and rank correlations for $\mathrm{CT}$ age 9 versus $Y B$ age 9 were significant.

Table 11

The linear regression fit $\mathrm{R}^{2}$ and Spearman's correlation coefficients for clone average $\mathrm{DBH}^{2}$ between Clone Trials and the Hansen Yield Block at different years for Hansen ( $n=22$ clones, 3 blocks per clone). Coefficients in italics are non-significant $(p>0.05)$.

\begin{tabular}{|c|c|c|c|c|c|c|c|c|c|}
\hline & \multirow[t]{3}{*}{ Age } & \multicolumn{8}{|c|}{ Clone Trial (Hansen) } \\
\hline & & \multirow[b]{2}{*}{3} & \multicolumn{3}{|c|}{$\mathrm{R}^{2}$} & \multicolumn{4}{|c|}{ Spearman's correlation coefficients $\left(r_{s}\right)$} \\
\hline & & & 4 & 5 & 9 & 3 & 4 & 5 & 9 \\
\hline \multirow{4}{*}{$\begin{array}{l}\text { Yield Block } \\
\text { (Hansen) }\end{array}$} & 3 & 0.68 & 0.61 & 0.34 & 0.03 & 0.75 & 0.74 & 0.55 & -0.14 \\
\hline & 4 & 0.47 & 0.53 & 0.34 & 0.01 & 0.64 & 0.68 & 0.59 & -0.08 \\
\hline & 5 & 0.23 & 0.34 & 0.26 & 0.01 & 0.47 & 0.56 & 0.57 & 0.15 \\
\hline & 9 & 0.10 & 0.03 & 0.01 & 0.29 & -0.23 & -0.14 & 0.14 & 0.46 \\
\hline
\end{tabular}

Clone growth performance in the Hansen CT at ages 3, 4, and 5 predicted the performance of the same clone in the Hansen YB at the same age, but not growth at age 9 in that YB. However, both $R^{2}$ and $r_{s}$ were significant for growth and rank correlations for CTs at age 9 versus Hansen YB at age 9. Coefficients of variation for $\mathrm{DBH}^{2}$ were similar for $\mathrm{CT}$ s and the $\mathrm{YB}$ at equal ages and decreased from age 3 to age 9 (data not shown), indicating that the selection of the best performing clones in the CTs for inclusion in the Hansen YB did not reduce growth variation in the $Y B$ and was not a factor in the correlation patterns. We also analyzed correlations between clone average $\mathrm{DBH}^{2}$ in $\mathrm{CT}$ s versus clone average cumulative basal area $\left(\mathrm{cm}^{2}\right)$ in $\mathrm{YBs}$, which gave the same pattern as $\mathrm{DBH}^{2}$ metrics, with slightly lower $\mathrm{R}^{2}$ and Spearman's Coefficients (data not shown).
In addition, we calculated the average genetic gain at age 9 (full rotation) in the Hansen YB (cumulative basal area of 9-tree plots, $\mathrm{cm}^{2}$ ) by comparing clone performance for the top 5 clones $\left(77^{\text {th }}\right.$ percentile) $\left(\mathrm{DBH}^{2}\right)$ selected in the Hansen $\mathrm{CT}$ at age 5 and 9 , using only the 22 clones that appeared in both YB and CT. We had to base genetic gain on the population mean of the Hansen YB, as no commercial check clones were included in the YB. This calculation gave a genetic gain of $5 \%(1 \%$ per year) for selection at 5 years in the $\mathrm{CT}$, and $11.3 \%$ genetic gain ( $1.3 \%$ per year) for selection at 9 years in the CT. Genetic gains in CTs versus commercial check clones in other of our populations are $27 \%-83 \%$ higher than those based on population means (Nelson et al., 2018; Nelson, Meilan et al., 2019; Nelson, Berguson et al., 2019), depending on site and 
population composition. Thus, the genetic gain comparison here is only relative and is not an estimate of meaningful genetic improvement against current commercial practice. Furthermore, these gain estimates are for only one YB and appear to be much lower than expected from previous genetic gain estimates based on many other CTs.

\section{Discussion}

As expected, age-age correlations for growth and rank are similar across the FFTs, CTs, and YBs (Table 4, 5, 6; $r_{s}$ must by squared to compare directly with $\mathrm{R}^{2}$ ). Rank is the most important selection criteria in the breeding process and ultimately should translate to growth and yield.

The age-age correlations for $\mathrm{DBH}^{2}$, actual and clone rank, had a similar pattern within the five FFTs-age 4 was a better predictor than age 3 of age 5 results, and the values for each age-age correlation were similar between sites (Table 4). The clone rank results are the most critical, and the results in Table 4 indicate that we can effectively select clones from the FFTs for further testing in the CTs based on growth rank at age 4 in the FFTs ( $r$ of $0.920-0.972$ for age 4 ranks versus age 5 ranks) instead of waiting to age 5 , saving one year in the testing process.

The age-age correlations for $\mathrm{DBH}^{2}$ in the CTs, actual and clone rank, had a similar pattern on all five sites; viz., correlations with age 9 or 10 results increased from age 3 to age 4 to age 5 (Table 5). Absolute values $R^{2}$ and $r_{s}$ for these same ageage correlations were much lower on one site, Smith (Table 5). Two of the five sites, Schultz and Captain, had $r_{s}$ values exceeding 0.82 for the age 5 to age 10 correlation-the other three sites $r_{s}$ ranged from 0.56 to 0.74 for the age 5 to age 9 or 10 correlation. The age 5 to age 10 rank correlation explained an average of $55 \%$ of the variation $\left(\mathrm{r}_{\mathrm{s}}^{2}\right)$, indicating that age 5 (halfrotation) is a moderately good age at which to select clones within the CTs for additional testing in the YBs. An average of $56 \%$ (range $40 \%$ to $80 \%$ for the five sites) of the clones ranked in the top ten ranking at age 10 in the CTs were in the top ten ranked clones at age 5 . This result for individual clones is better for clone selectivity than the report by Ghezehei et al. (2020), wherein only 3 top-ten clones out of the 66 clones tested for biomass at age 4 were still in the top ten at age 8 . It is highly likely that climate, site, and genetic composition can produce different age performance patterns in field trials, again illustrating the need for early selection studies under specific growing conditions, disease prevalence, and genetic composition.

These CT results in totality are consistent with those in most of the other age-age studies on Populus cited in the Introduction which indicate that clones can be selected at approximately one-half rotation. By selecting at age 5 , we miss about $44 \%$ of the clones that would have been selected in the $81^{\text {st }}$ percentile (top 10 clones) if selected at age 9 or 10 (Table 7); however, saving four or five years of testing with this procedure may be worth the possible reduction in genetic gain from the clone mis-selection at age 5 . Selection at age 5 in CTs is our standard operating procedure in the current testing process in Minnesota, so these results confirm our methods in a broad sense but do not allow us to reduce the age at which we select the best clones. However, growth performance of clones selected at age 5 in the Hansen CT are not correlated with growth of the same clones at age 9 in the $Y B$, whereas age 9 selection in the Hansen $C T$ identifies clones that perform well at age 9 in the Hansen YB (Table 11), although the significant $R^{2}$ and $r_{s}{ }^{2}$ only explain $29 \%$ and $21 \%$ of the variation for this correlation. This suggests selecting clones in CTs at age 9 or 10 (near-full rotation in Minnesota) will identify clones that will have superior growth performance at full rotation in the YBs, albeit with significant but low correlation. The Hansen CT and YB were on the same site in close proximity, suggesting that genotype $x$ environment interactions could reduce correlations between $\mathrm{CT}$ and $\mathrm{YB}$ even further when the $\mathrm{CT}$ and $\mathrm{YB}$ were on different sites. The effectiveness of full-rotation selection in $\mathrm{CT}$ indicates one aggressive strategy would be to choose superior clones at age 9 or 10 in the CTs and eliminate YB tests as a prerequisite for clone selection for commercial deployment. YB tests will still be necessary for precise estimates of biomass yield where required by a grower. This scenario would add 4 or 5 years onto the CT length ( 9 or 10 years instead of 5 years) but save 9 years by eliminating YB tests, for a net savings of at least 4 years. However, eliminating the YB step for clone selection would transfer some identification of clones susceptible to cankering during the nine years of YB to the commercial deployment stage. Another codicil is that the correlations of age 9 CT and age 9 YB growth and rank are based on data from only one site (Hansen).

Yield Blocks (Table 6) manifested only poor age-age correlations for age 5 versus age 10, with an $r_{s}$ of 0.481 for the Hansen site and non-significant $r_{s}$ for the LEA Grand Rapids site. This indicates that we must continue YBs to age 9 or 10 (full rotation) to obtain a reliable estimate of clone performance, as found by Stanton (2001). Similarly, Niemczyk and Thomas (2020) found that in northern climates of North America, 8 years is a reliable age at which to select fast-growing and disease-resistant poplar clones for commercial deployment. We already adopt this procedure in YBs to derive accurate biomass yield estimates for our clones. The low age-age correlations in YBs may reflect the possibility that clones perform differently from their growth in CTs when tested in the mono-clonal blocks of YBs, due to the more uniform competition in $\mathrm{YBs}$, although the significant correlation between growth in the Hansen CT and YB at age 9 (Table 11) argues against this explanation. Another factor is that in the Hansen YB cankering developed between ages 5 and 9. By age 9 in the Hansen YB, 6 out of 22 total clones, and 3 out of 10 DN clones, had significant or heavy cankering (data not shown), which could have affected growth and reduced the age-age correlations. The poor age-age correlations in the YBs are an example of the phenomenon described by Ghezehei et al. (2020), wherein some clones become less suitable, and others more suitable, with stand age. The development of significant cankering in the Hansen YB in 30 percent of the DN clones that had not shown cankering in the FFTs and CTs preceding the YB also 
demonstrate the value of testing clones for nearly full rotation length in the YBs to eliminate disease problems that were not manifest in earlier tests.

Canker incidence and severity in the CTs varied by taxon type and age and were generally much more variable by age than growth $\left(\mathrm{DBH}^{2}\right)$ (Table 8 and Fig. 3). Severe cankering (Canker Score 2) was almost non-existent in $\mathrm{D}$ and $\mathrm{D} x \mathrm{D}$ genotypes, prevalent in $\mathrm{D} \times \mathrm{M}$, and intermediate (but still low) in $\mathrm{D} \times \mathrm{N}$ (Fig. 2). These taxon cankering results were as expected, from our experience. Age-age correlations for canker score were low for all sites. The patterns of canker score with age did not consistently follow the expected pattern of increasing incidence and severity with age. In some instances, canker score estimates were higher at earlier than later ages (Fig. 3). This variability is undoubtedly a function of the subjectivity of the visual ordinal canker scoring system, including the possibility of not seeing cankers on some trees during some scoring sessions, as well as some cankers healing over by a later age. Therefore, apart from eliminating clones with heavy cankering at any age, our results indicate that we cannot judge a reliable age for predicting cankers before full rotation age. Our aim is the elimination of clones that show severe cankering at any age in the breeding and testing process, whether in NPTs, FFTs, CTs, or YBs. We can effectively identify clones prone to cankering by just scoring cankers at the endpoint of the CT process, whether this is half rotation (5 years) or full rotation ( 9 or 10 years), instead of our current practice, which has been to score cankering after each growing season.

For achieving disease resistance in poplars, a holistic plan is needed that tracks clones over time in regions where they are deployed. Disease resistance of poplars can change with geographic regions and climate and with evolution of the disease organism through mutations. Disease evolution can be expected to be faster with greater selection pressure on the disease organism, such as when large areas of poplar plantations are planted in a relatively small region. Our field testing for disease in poplars has some similarity to clinical testing of new pharmaceuticals. Not all side effects or efficacy failures are discovered in the clinical tests (field tests analogy)—some are not identified until the approved drug (poplar genotype analogy) is in use by the patient population over years or decades (commercial deployment of poplar genotype analogy). Fortunately for our focus on the $\mathrm{D} \times \mathrm{N}$ hybrids, there are some examples of durable Sphaerulina musiva (Septoria) canker resistance holding up over decades in some existing $\mathrm{D} x \mathrm{~N}$ hybrids, including Populus $x$ euramericana (DN34, Eugenei), Raverdeau, Robusta, 1-45/51, and Wisconsin 5 (unpublished long term field observations), which shows that resilient canker resistance is possible with other $\mathrm{D} x \mathrm{~N}$ hybrids. After many years, even some durable clones are likely to be susceptible to fungal diseases due to the evolution of the pathogen, making genetic diversity, deployment strategies, and periodic introduction of new cultivars essential (McDonald, 2014). This fact is one of the strongest justifications for continuing poplar breeding programs. Recent papers on Sphaerulina musiva in hybrid poplars provide background on canker resistance research (Dunnell et al., 2016; Niemczyk and Thomas, 2020; Tabima et al., 2020), including the importance of deploying resistant clones.

The overall correlation patterns for growth and rank for the unreplicated NPTs versus FFTs indicate that we can continue to measure coppice shoot lengths (Coppice 1 and/or Coppice 2) in the NPTs, because we need those measurements to choose families that have enough cuttings for the FFTs. There seems to be no advantage in using the other NPT growth measures for family selection. The fact that clone-to-clone regressions for all NPT growth measures versus FFT growth were significant, and that the NPT growth measures were correlated, is further evidence for simplifying the NPT measurement protocol by solely measuring coppice growth. This study is, to our knowledge, the first to correlate growth rate in NPTs with growth of families and clones in ensuing FFTs for hybrid poplars.

The almost complete lack of correlation of clone performance in FFTs versus CTs means that there is no evidence that clone means in the FFTs can be used to estimate clone means in the CTs with the clone replication levels that we commonly use in our FFTs. The data indicate that we should retain CTs in our breeding and testing process. Additive genetic variation is captured in the FFT, making family selection an essential step (Berguson et al., 2017). Indeed, multiple clones from single full sib families commonly are represented in the fastest growing $80^{\text {th }}-90^{\text {th }}$ percentile ranks of clones in our CTs (Nelson et al., 2018; Nelson, Berguson et al., 2019; Nelson, Meilan et al., 2019).

This lack of correlation of clone performance in FFTs versus CTs may be due to the clone replication levels ( $3-5$ replicates per clone) in the FFTs. It may also be true that selection in the FFTs is effective, but the effectiveness is not revealed in the correlation analyses because only the selected portion of the FFTs is carried forward to the CTs. The unselected portion of the FFTs may have underperformed in the CTs had they been tested there. If selection in the FFTs was indeed effective, then this should be reflected in lower clone variances and clonal repeatabilities in the CTs than in the FFTs, assuming comparable environmental variance. Table 10 indicates that this is the case, i.e., similar residual (environmental) variance in the FFTs and CTs and lower genetic variance and clonal repeatability in the CTs than in the FTs.

The lack of correlation for growth and clone rank between half-rotation in the Hansen CT and near-full rotation in the Hansen YB (age 9), but significant correlation at near-full rotation in both CT and YB (Table 11), suggests some value in using near-full rotation, rather than half rotation, for clone selection in the CTs. This would add 4 or 5 more years to the length of the CTs compared to our current procedure, but it may be worth the extra genetic gain that could ensue from better selection in both the CTs and YBs. As explained above, by selecting clones at age 5 in the CTs we miss 44 percent of the clones that are in the top ten $\left(81^{\text {st }}\right.$ percentile) for growth at full rotation in the $\mathrm{CTs}$. The decision of whether to select clones at age 5 or age 9 or 10 in the CTs should be an economic determination based on added genetic gain at the end of the pipeline (full rotation in the YB) from selection at near-full instead of half-rotation in the CTs versus the cost of adding four or five more years onto 
the CT segment of testing, an analysis that is beyond the scope of the current study. The most cautious approach would be to select clones at near-full rotation in the CTs, which would have the added advantage of providing four or five extra years to identify clones with canker susceptibility and remove such clones from further consideration for deployment. As explained above, one strategy would be to select superior clones for growth in CTs at near-full rotation (age 9), but eliminate YBs for clone selection, employing YBs only for estimating biomass yields. However, commercial deployment will likely only use a maximum of 10 clones at any given time, and maybe one can afford to lose some high performers if the scale (number of clones tested) of the breeding and testing program is sufficiently large (e.g., >100 clones) or there are only small differences between the growth rate of clones in the top $75^{\text {th }}$ percentile.

Summarizing the data, the most efficient and aggressive strategy for clone selection with acceptable accuracy and precision is as follows: 1 ) Measure only coppice shoot lengths in NPTs, eliminating measurement of seedling heights at ages 1 and 2 ; 2) Select superior clones and families at age 4 in the FFTs, instead of at age 5 , reducing FFTs by 1 year; 3 ) Select clones superior in growth rate in the CTs at age 9 , instead of age 5 , adding 4 years to the CT tests; 4 ) Eliminate YBs, except for providing estimates of biomass yield where needed, saving 9 years. The net savings in time with this strategy for FFTs, CTs, and $Y B s$ are $(-1+4-9)=6$ years saved, for a total testing time for clone selection of 13 years instead of 19 years, excluding the 3 or 4 years required for NPT and cutting production in stoolbeds; 5) Score canker presence and severity in the CTs only at the end point of the $\mathrm{CT}$ (half or full rotation), instead of after every growing season.

Although this study is highly valuable for our breeding program, the results are specific to the climate, soils, and genetic populations of the experiments. As such, the greatest values for applications to other breeding programs are the analytic approach to determine the most efficient clone testing schemes and the considerations that need to be included in such evaluations.

\section{Conclusions}

Our goal was to use correlation vectors to better define efficiency in the genotype testing process for our hybrid poplar program and other poplar programs that use a sequential procedure to derive superior clones. The results indicate that in FFTs we can select the fastest-growing families and clones within those families at 4 years instead of the current 5 years. In CTs, the age 5 to age 10 rank correlation explained an average of 74 $\%$ of the variation, indicating that age 5 (half rotation) is a moderately good age at which to select clones within the CTs for additional testing in the YBs. However, selecting at age 5 in the CTs missed $44 \%$ of the clones that were in the top ten clones ( $81^{\text {st }}$ percentile) at age 9 or 10 . In addition, clone growth and rank at age 5 in the CTs was not correlated with those growth parameters in the YBs at near-full rotation (age 9), but growth and rank at age 9 in the CTs was correlated with growth and rank at age 9 in the YB. These patterns indicate that a more accurate selection of clones will be obtained by selecting clones at age 9 in the CTs, instead of the current 5 years. Whether this extra time is worthwhile can be determined by a costbenefit analysis beyond the scope of the current study. The genetic gain per year at full rotation for selection at 9 years in a CT was one third higher than selection at 5 years in the same $\mathrm{CT}$, which gives a relative idea of the tradeoffs for the early and late selection options. Nursery Progeny Tests can be simplified to only measuring the shoot lengths of coppice in stoolbeds, eliminating $2-3$ other measurements that we currently make. The clone replication that we currently use in FFTs is not sufficient for us to select superior clones in FFTs without the CTs that follow FFTs in our current process, i.e., we cannot eliminate CTs. Except for eliminating clones with heavy cankering at any age and differentiating canker prevalence and severity for different taxon groups ( $D, D \times D, D \times M, D \times N, N, N \times M)$, from the data presented here we cannot judge a reliable age for predicting cankers at full rotation, probably due to the accuracy and precision of the canker scoring method. The correct testing perspective to increase disease resistance is to eliminate clones that show severe cankering at any age in the total breeding protocol, whether in NPTs, FFTs, CTs, YBs, or after commercial deployment.

\section{Acknowledgements}

At the University of Minnesota's NRRI in Duluth, development and testing of NRRI clones was funded by State of Minnesota appropriations to the Minnesota Hybrid Poplar Research Cooperative (MHPRC), State Special appropriations to the University of Minnesota Duluth Natural Resources Research Institute (NRRI), Minnesota Agricultural Utilization Research Institute (AURI) and U.S. DOE BETO Sun Grant Initiative Poplar Woody Crops Program (contract \# DEFC36-05GO85041). In addition, the following companies contributed through their membership in the MHPRC: Verso Corporation, Champion International, International Paper, Boise Cascade, Potlatch Corporation (now PotlatchDeltic), UPM-Blandin and Minnesota Power (MN Power). Verso Corporation generously allowed us to embed most of the field plots in this study within their commercial hybrid poplar plantations and provided site preparation and maintenance. Analysis and writing were funded by the USDANIFA Agriculture and Food Research Initiative Competitive Grants Program Sustainable Bioenergy and Bioproducts Challenge Area (grant no. 2018-68005-27635/project accession no. 1015244). Some clones in the tests were provided by the U.S. Forest Service Rhinelander Forestry Sciences Laboratory (Dr. Don Riemenschneider). Parents from outside the NRRI program used in producing inter-specific hybrids at NRRI were provided by the University of Minnesota (the late Dr. Carl Mohn's program), University of Toronto (the late Dr. Louis Zsuffa), and lowa State University (the late Dr. Rick Hall). Anda 
Bellamy is gratefully acknowledged for editing the paper for journal submission. An anonymous reviewer is acknowledged for materially improving the manuscript.

\section{Appendix A. Supplementary Electronic Materials Supplementary data to this article can be found online.}

\section{References}

Ares A (2002) Changes through time in traits of poplar clones in selection trials. New Forests 23:105-119. https://doi.org/10.1023/A:1015687708505

Bacenetti J, Bergante S, Facciotto G, Fiala M (2016) Woody biofuel production from short rotation coppice in Italy: Environmental-impact assessment of different species and crop management. Biomass \& Bioenergy 94:209-219. http://dx.doi.org/10.1016/j.biombioe.2016.09.002

Baltunis B, Brawner JT (2010) Clonal stability in Pinus radiata across New Zealand and Australia. I. Growth and form traits. New Forests 40: 305-322. https://doi.org/10.1007/s11056-010-9201-4

Berguson W, Eaton J, Stanton B (2010) Development of hybrid poplar for commercial production in the United States: The Pacific Northwest and Minnesota experience. In: Braun R, D Karlen and D Johnson (eds) Sustainable Feedstocks for Advanced Biofuels, Sustainable Alternative Fuel Feedstock Opportunities, Challenges and Roadmaps for Six U.S. Regions. Proceedings, Sustainable Feedstock for Advance Biofuels Workshop. Ankeny, IA: Soil and Water Conservation Society, pp 282-299.

Berguson WE, McMahon BG, Riemenschneider DE (2017) Additive and non-additive genetic variances for tree growth in several hybrid poplar populations and implications regarding breeding strategy. Silvae Genetica 66:3339. https://doi.org/10.1515/sg-2017-0005

Bisoffi S (1993) Age-age correlations for the evaluation of forest reproductive material. In: Terrasson D (ed) Proceedings, Quality of Forest Reproductive Material in the Field of Application of European Community Rules, European Commission, Paris, 9-10 December, 1993. CEMAGREF Editions, pp 75-91.

Bisoffi S, Gullberg U (1996) Poplar breeding and selection strategies. In: Stettler RF, HD Bradshaw Jr, PE Heilman and TM Hinckley (eds) Biology of Populus and its Implications for Management and Conservation - Part I. Ottawa, ON NRC Research Press, National Research Council of Canada, pp 139-158.

Brown KR, Beall FD, Hogan GD (1996) Establishment-year height growth in hybrid poplars; relations with longer-term survival. New Forests 12(2):175186

Chiba S, Nagata Y (1972) Rust resistance and growth of Populus maximowiczii clones selected from the progenies of intraspecific hybridization. Tokyo, Japan: Proceedings, IUFRO Genetics - SABRAO Joint Symposia, C-6(V), pp $1-7$

Dunnell KL, Berguson B, McMahon B, LeBoldus JM (2016) Variation in resistance of Populus nigra to Sphaerulina musiva in the North-Central United States. Plant Disease 100:287-291.https://doi.org/10.1094/pdis-05-15-0516-re

Foster GS (1986) Provenance variation of eastern cottonwood in the lower Mississippi Valley. Silvae Genetica 35(1):32-38.

Ghezehei SB, Nichols EG, Maier CA, Hazel DW (2019) Adaptability of Populus to physiography and growing conditions in the Southeastern USA. Forests 10:118. https://doi.org/10.3390/f10020118

Ghezehei SB, Wright J, Zalesny RS, Guthrie Nichols E, Hazel DW (2020) Matching site-suitable poplars to rotation length for optimized productivity. Forest Ecology and Management 457:117670 https://doi.org/10.1016/j.foreco.2019.117670

Gwaze DP, Bridgewater FE, Byram TD, Woolliams JA, Williams CG (2000) Predicting age-age genetic correlations in tree-breeding programs; a case study of Pinus taeda L. Theoretical Applications of Genetics 100:199-206. https://doi.org/10.1007/s001220050027

Kaczmarek DJ, Coyle DR, Coleman MD (2013) Survival and growth of a range of Populus clones in central South Carolina USA through age ten: Do early as- sessments reflect longer-term survival and growth trends? Biomass \& Bioenergy 49:260-272. https://doi.org/10.1016/j.biombioe.2012.12.005 Krinard RM (1988) Volume equations for plantation cottonwood trees (Populus deltoides). USDA Forest Service, Southern Forest Experiment Station, SO347, 4 p. https://doi.org/10.2737/SO-RN-347.

Kumar D, Singh NB (2001) Age-age correlations for early selection of clones of Populus in India. Silvae Genetica 50(3):103-108.

Lazarus W, Headley WL, Zalesny RS (2015) Impacts of supplyshed-level differences in productivity and land costs on the economics of hybrid poplar production in Minnesota, USA. Bioenergy Research 8(1):231-248. https://doi.org/10.1007/s12155-014-9520-y

Libby WJ (1987) Testing for clonal forestry. Annales Forestales 13(1-2):69-75. McDonald BA (2014) Using dynamic diversity to achieve durable disease resistance in agricultural ecosystems. Tropical Plant Pathology 39(3):191-196 https://doi.org/10.1590/S1982-56762014000300001

Mohn CA, Randall WK (1971) Inheritance and correlation of growth characters in Populus deltoides. Silvae Genetica 20:182-184.

Mohrdiek O (1979) Juvenile-mature and trait correlations in some aspen and poplar trials. Silvae Genetica 28:107-111.

Nelson ND, Berguson WE, McMahon BG, Cai M, Buchman DJ (2018) Growth performance and stability of hybrid poplar clones in simultaneous tests on six sites. Biomass \& Bioenergy 118:115-125. https://doi.org/10.1016/j.biombioe.2018.08.007

Nelson ND, Berguson WE, McMahon BG, Meilan R, Smart LB, Gouker FE, Bloese P, Miller R, Volk TA, Cai M, Buchman D (2019) Discovery of geographically robust hybrid poplar clones. Silvae Genetica 68(1):101-110. https://doi.org/10.2478/sg-2019-0018

Nelson ND, Meilan R, Berguson WE, McMahon BG, Cai M, Buchman D (2019) Growth performance of hybrid poplar clones on two agricultural sites with and without early irrigation and fertilization. Silvae Genetica 68(1):58-66. https://doi.org/10.2478/sg-2019-0011

Niemczyk M, Thomas BR (2020) Growth parameters and resistance to Sphaerulina musiva-induced canker are more important than wood density for increasing genetic gain from selection of Populus spp. Hybrids for northern climates. Annals of Forest Science 77:26. https://doi.org/10.1007/s13595-020-0931-y

Randall WK, Cooper DT (1973) Predicted genotypic gain from cottonwood clonal tests. Silvae Genetica 22:165-167.

Stanton BJ (2001) Clonal variation in basal area growth patterns during stand development in hybrid poplar. Can. J. For. Res. 31 (12):2059-2066. https://doi.org/10.1139/x01-150

Tabima JF, Sondreli KL, Kerio S, Feau N, Sakalidis ML, Hamelin RC, LeBoldus JM (2020) Population genomic analyses reveal connectivity via human-mediated transport across Populus plantations in North America and an undescribed subpopulation of Sphaerulina musiva. MPMI 33(2):189-199. https://doi.org/10.1094/MPMI-05-19-0131-R

Tsarev AP (1977) Minimum age for evaluating growth rate of Populus in variety trials. Lesovendenie 3:67-71.

US Department of Energy (US DOE) (2016) 2016 Billion-Ton Report: Advancing Domestic Resources for a Thriving Bioeconomy. In: Langholtz MH, BJ Stokes and LM Eaton (Leads) Volume 1: Economic Availability of Feedstocks. Oak Ridge, TN: Oak Ridge National Laboratory, ORNL/TM-2016/160. http://doi.org/10.2172/1271651

White CC, Adams WT, Neale DB (2007) Forest Genetics. Wallingford Oxfordshire, United Kingdom: CAB International. https://doi.org/10.1079/9781845932855.0000

Wilkinson RC (1973) Inheritance and correlation of growth characters in hybrid poplar clones. In: Proceedings, Northeastern Forest Tree Improvement Conference. Durham, NH: University of New Hampshire, pp 121-130.

Wu HX (1999) Study of early selection in tree breeding. 2. Advantage of early selection through shortening the breeding cycle. Silvae Genetica 48(2):78-83.

Yaneza, MA, Zamudio F, Espinoza S, Ivkovic M, Guerra F, Espinosa C, Baettig RM (2019) Genetic variation and growth stability of hybrid poplars in high-density short-rotation coppice stands in central Chile. Biomass and Bioenergy 120:84-90. https://doi.org/10.1016/i.biombioe.2018.11.011

Ying CC, Bagley WT (1976) Genetic variation in eastern cottonwood in an eastern Nebraska provenance study. Silvae Genetica 25:67-73. 
Zhang P, Wu F, Kang X (2013) Genetic control of fiber properties and growth in triploid hybrid clones of Populus tomentosa. Scandinavian Journal of Forest Research 28(7):621-630. http://dx.doi.org/10.1080/02827581.2013.829868 